\title{
Acute hepatitis associated with the use of natural product camu-camu
}

\author{
Raffaela Bertoli ${ }^{1}$, Luca Mazzuchelli ${ }^{2}$, Andreas Cerny ${ }^{3}$ \\ ${ }^{1}$ Servizio di Consulenza sui Farmaci e Centro Regionale di Farmacovigilanza, Ospedale Regionale di Lugano, Lugano, Switzerland \\ ${ }^{2}$ Istituto Cantonale di Patologia, Locarno, Switzerland \\ ${ }^{3}$ Clinica Luganese Moncucco, Lugano, Switzerland \\ Email: farmacovigilanza@bluewin.ch
}

Received 12 July 2012; revised 5 May 2013; accepted 10 July 2013

Copyright (c) 2013 Raffaela Bertoli et al. This is an open access article distributed under the Creative Commons Attribution License, which permits unrestricted use, distribution, and reproduction in any medium, provided the original work is properly cited.

\begin{abstract}
A 45-year-old previously healthy caucasian man was admitted for pruritus, scleral icterus and dark urine. The patient was reported to have taken a spoon of a preparation containing camu-camu (myrciaria dubia) a day. He took no other drugs and did not drink alcohol or use illicit substance. Laboratory studies reveiled an elevated aspartate transaminase of $403 \mathrm{U} / \mathrm{L}$, and alanine transaminase of $1185 \mathrm{U} / \mathrm{L}$, alkaline phosphatase of $335 \mathrm{U} / \mathrm{L}$, gamma glutamyl transpeptidase of $300 \mathrm{U} / \mathrm{L}$, and elevated total bilirubin of $142 \mu \mathrm{mol} / \mathrm{L}$. His complete blood count was normal. Tests for viral, metabolic or autoimmune causes of liver injury were negative. Liver biopsy demonstrated centrilobular hepatocellular damage was compatible with drug toxicity which was not of very recent origin. Clinical and laboratory signs of liver injury gradually improved and the patient was discharged. Myrciaria dubia is used as a dietary supplement with antioxidant properties. To our knowledge, this is the first report of liver injury probably related to use of camu-camu. Exclusion of other causes and the histological diagnosis were compatible with drug toxicity render camu-camu which was most likely as the cause of acute heaptitis most likely. It is important to increase the awareness of both clinicians and patients about the potential dangers of herbal remedies in absence of reliable studies of clinical efficacy and benefit-risk assessment.
\end{abstract}

Keywords: Camu-Camu; Herbal Remedies; Hepatitis; Liver Damage

\section{INTRODUCTION}

The use of complementary and alternative medicine, above all herbal medication usage for various ailments, is increasing [1,2]. The use is highest in persons between the ages of 35 and 55 years [3,4]. These agents escape requirement for proof of safety and efficacy as they are often considered "dietary supplements". Physicians are often unaware that their patients are using herbal remedies. Fewer than 40 percent of patients disclose to their physician that they are using these products [3]. Because they are considered "natural," there is a perception that herbal preparations are without adverse effects. Instead, some of these herbal mixtures have been reported to cause severe side effects including hepatotoxicity and occasionally lead to acute liver failure and liver transplantation. There are no precise estimates of the frequency of hepatotoxicity which is attributable to herbal and dietary supplements, the United States Drug-Induced Liver Injury Network (DILIN) found that about ten percent of cases of drug-induced liver injury could be attributed to herbal and dietary supplements [5].

We present a case of an acute hepatitis probably related to the use of a dietary supplements containing camu-camu.

\section{CASE REPORT}

A 45-year-old caucasian man was admitted at the end of September for pruritus, scleral icterus and dark urine noticed for two weeks accompanied by fever and vomiting.

The medical history and family history were unremarkable. The patient reported, to have taken a spoon a day of a preparation containing camu-camu (myrciaria dubia) two months ago for a period of approximately 10 days. He took no other drugs and did not drink alcohol or use illicit substance. There was no history of transfusions, tattoos, or tick contacts. A month before admission he had travelled to Argentina, were he began to report weight loss and loss of appetite. Physical examination was unremarkable apart from jaundice and mildly elevated body 
temperature.

Laboratory studies revealed an elevated aspartate aminotransferase of $403 \mathrm{U} / \mathrm{L}$, and alanine aminotransferase of $1185 \mathrm{U} / \mathrm{L}$, alkaline phosphatase of $335 \mathrm{U} / \mathrm{L}$, gammaglutamyl transpeptidase of $300 \mathrm{U} / \mathrm{L}$, and elevated total bilirubin of 142 umol/L. His complete blood count was normal.

Tests for Hepatitis A, B, C and E, EBV and CMV could rule out viral hepatitis, metabolic or autoimmune causes of liver injury. A MR-Cholangiography showed no abnormalities.

A percutaneous liver biopsy demonstrated centrilobular hepatocellular damage. There was no evidence for cholestasis, no necrotic hepatocytes were observed. Absence of eosinophilia or epitheloid granulomas. No fibrosis was identified. Histology was reported to be compatible with drug toxicity of not very recent origin (Figure 1).

Clinical and laboratory signs of liver injury gradually

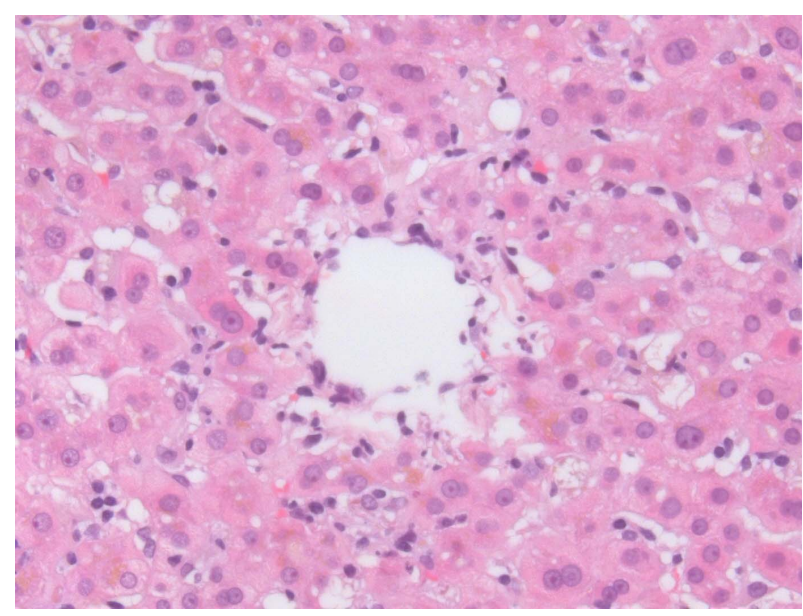

(a)

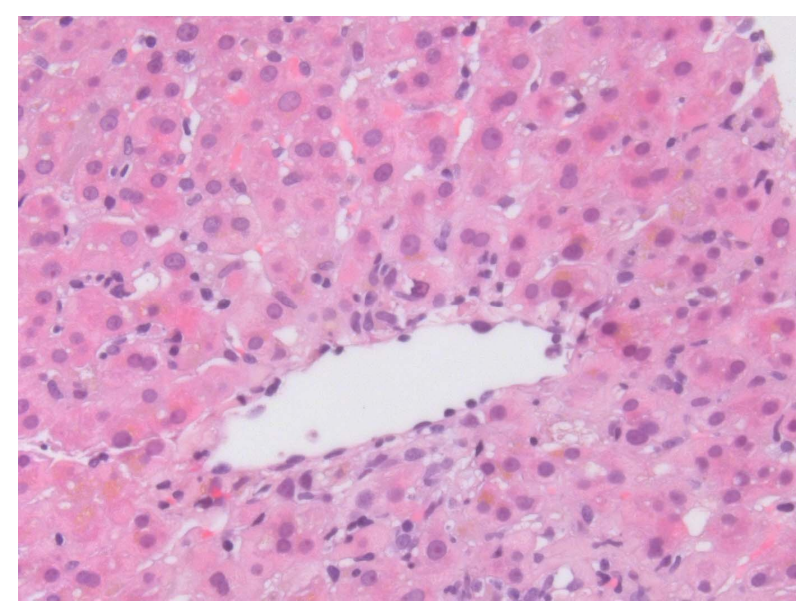

(b)

Figure 1. Liver section showing an inflammatory reaction around the central vein accompanied by signs of hepatocyte loss. improved and the patient was discharged.

\section{DISCUSSION}

Myrciaria dubia, commonly known as camu-camu, is an amazonian fruit that offers very high content of vitamin C. It is used as a dietary supplement with antioxidant properties. Documentation of traditional camu-camu use is scarce. It is unlikely that in traditional Amazonian societies camuc-camu had ever been nutritionally relevant, and the fruit is extremely acidic. There are no publications on medicinal or therapeutic properties of camucamu in the biomedical literature. Herbal supplement companies that market camu-camu extracts in powders and pills claim it can prevent and cure viral infections such as influenza.

To our knowledge, this is the first report of liver injury probably related to use of camu-camu. Exclusion of other causes and the histological diagnosis were compatible with drug toxicity render camu-camu which was most likely as the cause of acute hepatitis most likely. According to Naranjo et al. [6] adverse-reaction probability scale, camu-camu was the probable cause of hepatotoxicity in this patient. There are no specific tests or markers to confirm a diagnosis of drug-induced liver injury. In 1990, an expert panel developed criteria for assessing the causality of drug-induced liver injury [7]. The proof that a drug causes liver injury relies on both chronological and clinical criteria [8]. Several scoring systems have been proposed to standardize such assessment, the best known of which include the RU-CAM (Roussel Uclaf Causality Assessment Method) scale more recently called the CIOMS (Council for International Organizations of Medical Sciences) scale [9]. While these scales have not been validated in the setting of herbal medicine, they may be useful. Also causality assessment with the CIOMS scale shows a probable causality ( 6 points).

In conclusion, the use of herbal drugs should always be considered in cases of liver injury. It is important to increase the awareness of both clinicians and patients about the potential dangers of herbal remedies, dietary supplements and other complementary therapies in absence of reliable studies of clinical efficacy and benefitrisk assessment.

\section{REFERENCES}

[1] Tindle, H.A., Davis, R.B., Phillips, R.S. and Eisenberg, D.M. (2005) Trends in use of complementary and alternative medicine by US adults: 1997-2002. Alternative Therapies, Health and Medicine, 11, 42-49.

[2] Xue, C.C., Zhang, A.L., Lin, V., Da Costa, C. and Story, D.F. (2007) Complementary and alternative medicine use in Australia: A national population-based survey. The Journal of Alternative and Complementary Medicine, 13, 
643-650. doi:10.1089/acm.2006.6355

[3] Eisenberg, D.M., et al. (1998) Trends in alternative medicine use in the United States, 1990-1997: Results of a follow-up national survey. JAMA, 280, 1569-1575. doi:10.1001/jama.280.18.1569

[4] Ni, H., et al. (2002) Utilization of complementary and alternative medicine by United States adults: Results from the 1999 national health interview survey. Medical Care, 40, 353-358. doi:10.1097/00005650-200204000-00011

[5] Chalasani, N., et al. (2008) Causes, clinical features, and outcomes from a prospective study of drug-induced liver injury in the United States. Gastroenterology, 135, 1924. doi:10.1053/j.gastro.2008.09.011

[6] Naranjo, C.A., Busto, U., Sellers, E.M., et al. (1981) A method for estimating the probability of adverse drug re- actions. Clinical and Pharmacological Therapy, 30, 239245. doi:10.1038/clpt.1981.154

[7] Benichou, C. (1990) Criteria of drug-induced liver disorders. Report of an international consensus meeting. Journal of Hepatology, 11, 272. doi:10.1016/0168-8278(90)90124-A

[8] Larrey, D. (2002) Epidemiology and individual susceptibility to adverse drug reactions affecting the liver. Semin Liver Disease, 22, 145. doi:10.1055/s-2002-30101

[9] Danan, G. and Benichou, C. (1993) Causality assessment of adverse reactions to drugs-I. A novel method based on the conclusions of international consensus meetings: Application to drug-induced liver incurie. Journal of Clinical Epidemiology, 46, 1323. doi:10.1016/0895-4356(93)90101-6 